\title{
Galvanic cathodic protection of corroded reinforced concrete structures
}

\author{
David Whitmore ${ }^{1^{*}}$ \\ ${ }^{1}$ Vector Corrosion Technologies, Winnipeg, Manitoba, Canada
}

\begin{abstract}
Reinforced concrete structures can be designed and maintained to achieve long service lives, even in aggressive chloride environments. Unfortunately, many structures, such as bridges, piers, and wharves, show signs of active corrosion (e.g. rust staining, concrete spalling, etc.) in as little as 5 to 10 years. Left unchecked, chloride induced corrosion can lead to major structural problems. Many severely corroded structures have been replaced at great expense and with significant disruption to the public. As an alternative to demolition and replacement, a viable option is to repair and protect severely deteriorated structures utilizing a galvanic encasement that both structurally upgrades and catholically protects the structure. This approach can provide an effective, low maintenance galvanic cathodic protection solution for deteriorated concrete structures. Galvanic encasements consist of distributed galvanic anodes embedded in a concrete overlay or concrete jacket. The galvanic encasement may include additional reinforcing steel to create a one-step structural repair and protection system. This paper presents case studies on the use of galvanic encasements to repair and protect reinforced concrete structures. Long term monitoring of field projects over more than 10 years indicates that effective cathodic protection can be provided for 20 to $40+$ years.
\end{abstract}

\section{Introduction}

Chloride induced corrosion of reinforcing steel in concrete is a major problem worldwide. Chlorides can be introduced into the concrete via exposure to seawater, de-icing chemicals, or in certain cases as contaminants or additives in the initial concrete mix. This leads to localized breakdown of the normally passive reinforcing steel and results in pitting corrosion (Figure 1).

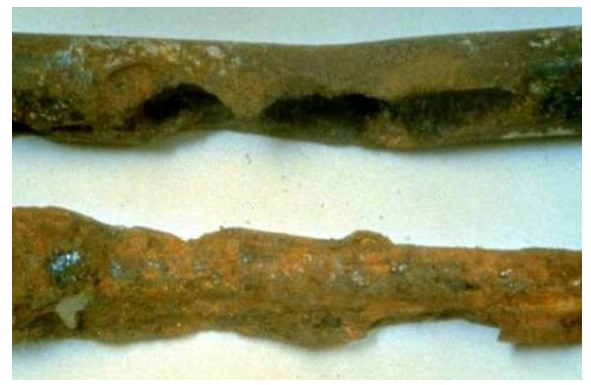

Fig. 1. Chloride-induced pitting corrosion on concrete reinforcement

Corrosion leads to concrete deterioration and local patch repairs are often performed to address this concrete damage. Patch repairs are completed by removing the cracked or spalled concrete, cleaning the steel locally and filling the cavity with fresh repair mortar or concrete (Figure 2[A]). Unless all chloride-contaminated concrete around the patch is removed, however, the repair process can lead to the formation of incipient anodes (Figure $2[\mathrm{~A}]$ ) where new corrosion sites just outside the repaired area are driven by the difference in potential between the steel in the chloride contaminated and chloride-free sections $[\mathrm{i}, \mathrm{ii}]$.

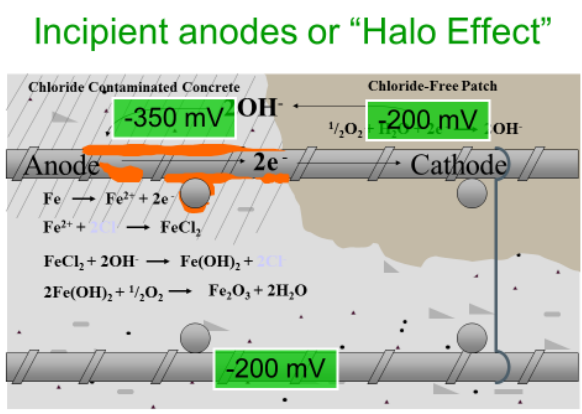

Fig. 2[A]. Illustration of corrosion around concrete patch repair

This 'localized' problem has been eradicated by placement of discrete alkali-activated (Type 1A) galvanic anodes around the perimeter of patch repairs (Figure 2[B]) which control incipient anode formation and avoid corrosion initiation [iii,iv]. One of the oldest monitored projects where such anodes were used has been monitored for over 15 years and is showing no signs of failure. The anodes are continuing to produce sufficient galvanic current to achieve cathodic 
prevention (corrosion prevention) [v,vi] and avoid corrosion initiation in the vicinity of the repairs.

\section{Installed Galvanic Anode}

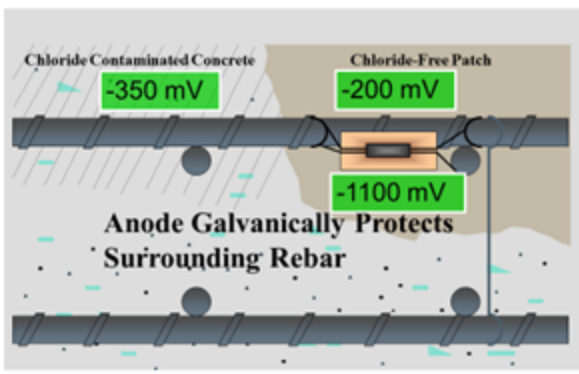

Fig. 2[B]. Illustration of localized galvanic protection protecting the remaining concrete adjacent to concrete repair

Similar galvanic anodes have been used in either a grid configuration or as elongated chains to mitigate low level steel corrosion in undamaged reinforced concrete elements which were at risk of corrosion. This application is known as corrosion control where corrosion cannot initiate at new locations and locations where corrosion is already occurring is gradually reduced. These applications have also shown consistently good performance [vii].

\section{Performance of Localized Galvanic Anodes}

Specially designed Type 1A discrete galvanic anodes were first installed in the late 1990's to provide cathodic prevention (corrosion prevention) in concrete patch repairs. One of the first monitored installations was on a pier cap of a bridge in the UK (Figure 3).

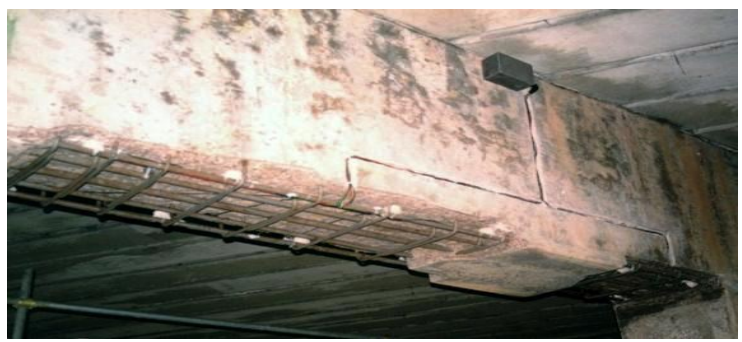

Fig. 3. Monitored Type 1A discrete galvanic anodes during installation on a bridge pier cap

Twelve anodes on this project were connected through a junction box so they could be monitored long term. The anodes were installed along the perimeter of the repairs. The pier cap suffered from corrosion due to chloride contamination of up to $2 \% \mathrm{Cl}^{-}$by weight of cement at the depth of the steel. Figure 4 summarises the mean current density delivered by the anodes to the steel. The range is comfortably within the $0.2-2.0 \mathrm{~mA} / \mathrm{m}^{2}$ current density suggested for cathodic prevention over the entire 15-year period (Figure 4). More importantly, there is no evidence of corrosion initiation either within or around the periphery of the patch repair. Removal and examination of two anodes showed that over half the zinc mass was still available for continued protection such that the service life of the anodes is likely to be 25 to 35 years.

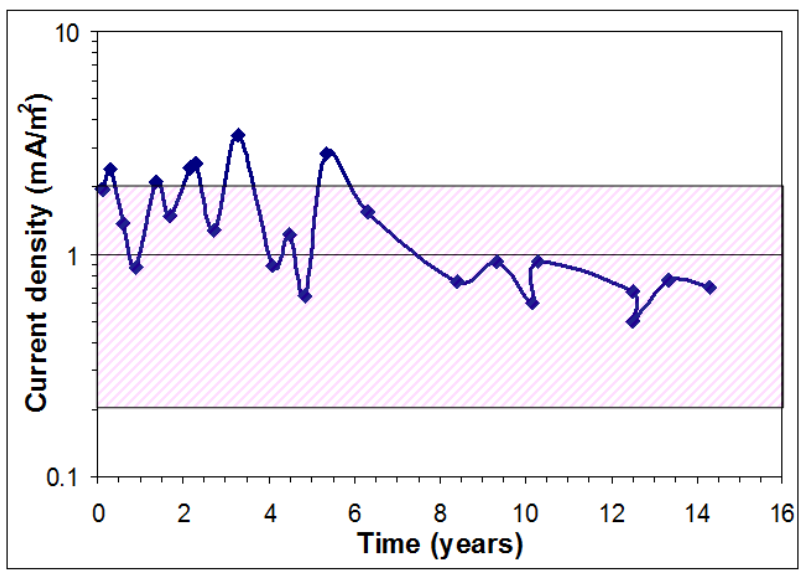

Fig. 4. Current density to the reinforcing steel $\left(\mathrm{mAm}^{2}\right)$ plotted vs. time. Shaded area indicates current density for cathodic prevention (corrosion prevention) as per EN12696 (0.2 to 2.0 $\left.\mathrm{mA} / \mathrm{m}^{2}\right)$.

Work completed by the US Bureau of Reclamation under ACI 2020 has shown the use of galvanic anodes to be a very effective repair strategy compared to other common repair methods (Figure 5). This work was completed on reinforced concrete slabs which were exposed to periodic salt water ponding.

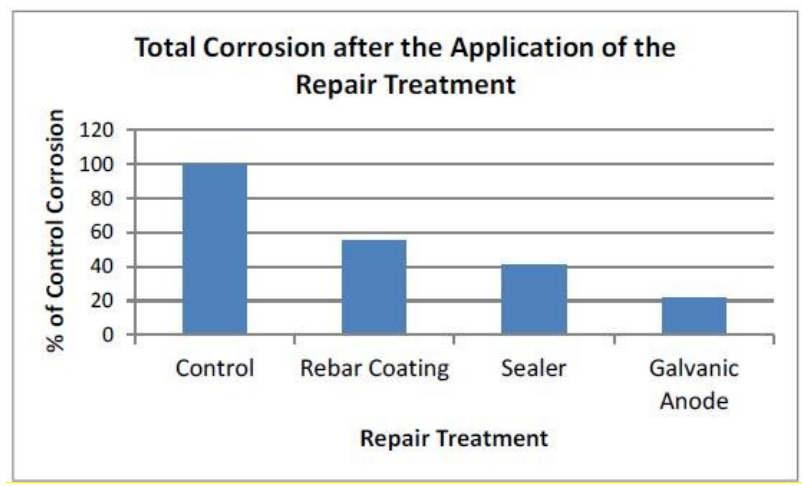

Fig. 5. Comparison of the effectiveness of different repair methods in reducing total corrosion.

\section{Galvanic Cathodic Protection}

Historically, impressed current was required to supply sufficient current to the reinforcing steel to achieve cathodic protection. This is no longer the case as properly designed galvanic encasements using high output, alkali-activated, long-life distributed galvanic anodes do not introduce any corrosive constituents into the concrete and can be designed to provide sufficient current density to polarize the reinforcing steel and meet all NACE / EN cathodic protection criteria.

This portion of the paper describes projects where this innovative techniques has been used to provide longterm galvanic cathodic protection to bridge abutments, decks and columns.

a) Ohio DOT Bridge Substructure 
b) Ontario Ministry of Transportation Bridge Deck

c) Florida DOT Marine Substructures

\subsection{Ohio DOT Substructure}

This bridge was repaired in July 2005 with an alkaliactivated galvanic encasement designed to provide longterm cathodic protection to the reinforcing steel. The ODOT bridge substructure repair included re-facing the abutments of multiple bridges. The re-facing included distributed, embedded galvanic anodes which were designed to provide cathodic protection (Figures $6 \&$ 7[A]) for all reinforcing steel in the entire abutment. The bridge has been monitored as part of an ODOT technology evaluation program since May 2005. (Figure $7[\mathrm{~B}])$.

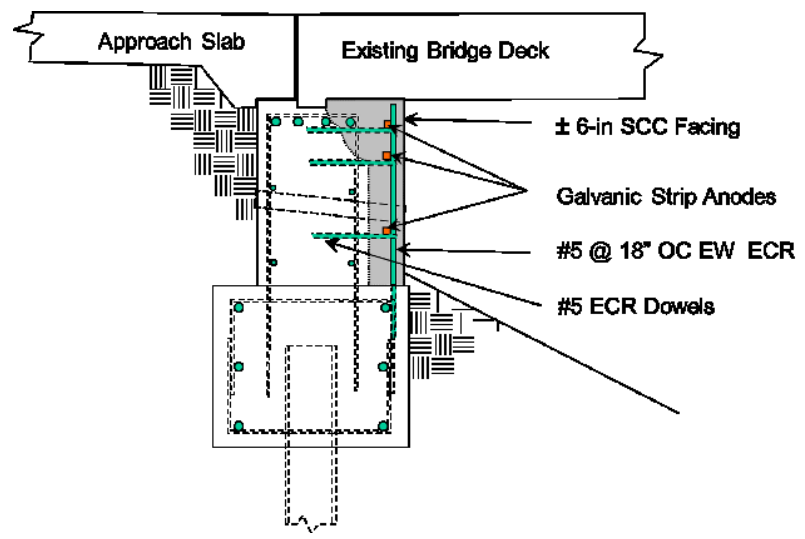

Fig. 6. Galvanic encasement of abutment

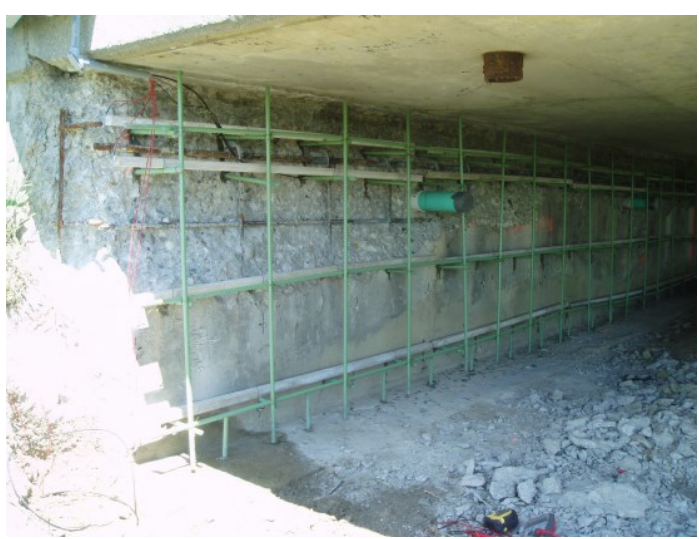

Fig. 7[A]. Galvanic distributed anodes installed across face of abutment

The monitoring program included the installation of dataloggers to monitor the current flowing from the galvanic anodes to the reinforcing steel as well as the temperature of the concrete itself (Figure 8). In addition to the measurements taken by the dataloggers, current, potentials and polarization measurements were taken manually when personnel visited the project site (Figure 9).

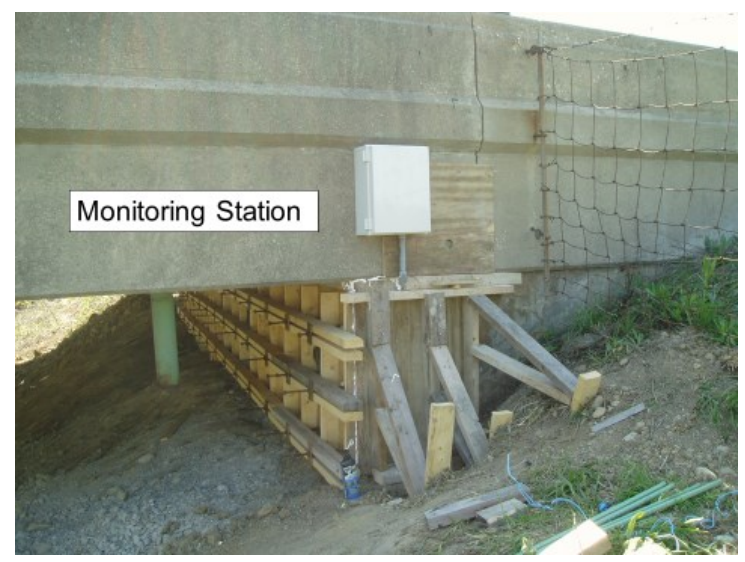

Fig. $7[\mathbf{B}]$. Distributed anode system monitoring cabinet

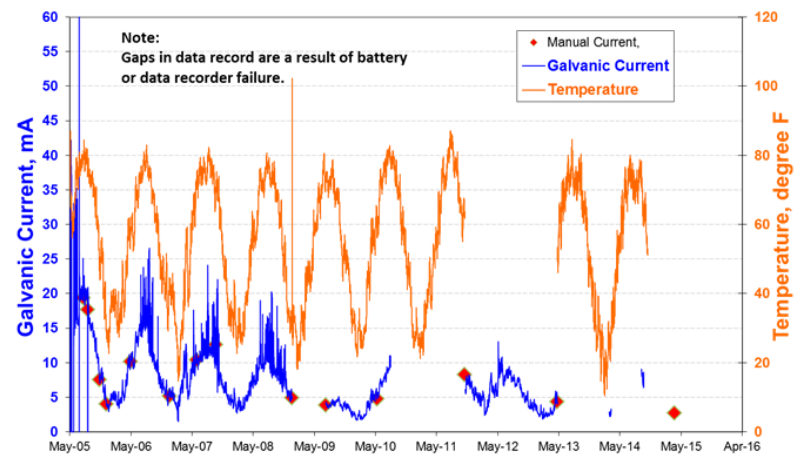

Date

Fig. 8. Ohio DOT galvanic current and temperature history

\begin{tabular}{|c|c|c|c|}
\hline Date & Temp & $\mathrm{mA} / \mathrm{m} 2$ & Polarization \\
\hline $5 / 6 / 05$ & (C) & 37.7 & (mV) \\
\hline $8 / 16 / 05$ & 31 & 12.9 & 333 \\
\hline $12 / 7 / 05$ & 11 & 3.2 & 339 \\
\hline $5 / 1 / 06$ & 14 & 7.5 & 335 \\
\hline $5 / 30 / 07$ & 26 & 7.5 & 446 \\
\hline $12 / 09 / 08$ & 4 & 3.3 & 470 \\
\hline $5 / 11 / 2010$ & 12 & 3.3 & 485 \\
\hline 10/16/2011 & 22 & 6.6 & 488 \\
\hline $4 / 22 / 2013$ & 21 & 3.3 & 425 \\
\hline $3 / 24 / 2015$ & 2 & 2.2 & 381 \\
\hline
\end{tabular}

Fig. 9. Ohio DOT Galvanic CP Polarization Data

The performance data indicates that the installed galvanic cathodic protection system is performing well. The following cathodic protection criteria are satisfied:

- Cathodic polarization shift exceeds $100 \mathrm{mV}$,

- the polarized instant-off potential has generally been more negative than $-850 \mathrm{mV}$ vs CSE, and

- Polarization of the reinforcing steel is requiring less current density over time. Calculated service life is now more than double the design service life as the average current density has been significantly less than the design current density.

The abutment is in very good condition 10 years after the galvanic encasement was completed. Prior to 
completing this galvanic encasement, this type of abutment was being repaired every 5 to 7 years.

The performance of this galvanic encasement installation verifies the system has been providing galvanic cathodic protection for over 10 years. Service life calculations indicate there is sufficient zinc for the system to provide corrosion protection for 35 years.

\subsection{Ontario Ministry of Transportation (MTO) Bridge Deck Overlay}

Due to long-term exposure to de-icing chemicals the bridge deck of the North Otter Creek Bridge (MTO) was chloride contaminated and required repair. In 2003, the Ontario Ministry of Transportation (MTO) decided to place a galvanic cathodic protection overlay on the bridge deck.

The bridge deck was prepared by milling off a portion of the existing concrete cover. As a result, the majority of the existing reinforcing steel was to remain in chloride contaminated concrete. A 'distributed' galvanic cathodic protection system consisting of elongated galvanic anodes placed in rows and connected to the existing reinforcing steel was installed. The galvanic anodes consisted of a zinc core encased in a low resistivity alkali-activated mortar shell and were prefabricated to fit the dimensions of the deck. (Figure 10)

A carbon fiber grid was installed to reduce shrinkage and minimize cracking of the 2.5 inch $(60 \mathrm{~mm})$ thick silica fume deck overlay (Figure 10).

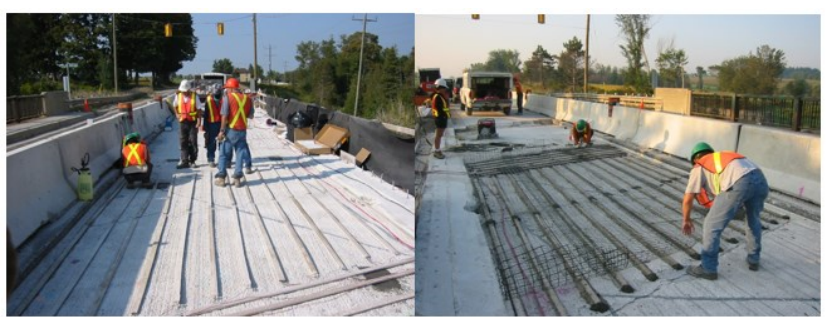

Fig. 10. Installation of distributed galvanic anodes and carbon fiber grid prior to concrete overlay.

The bridge deck has been monitored since 2003 and remains in good physical condition. The galvanic cathodic protection overlay is providing over $100 \mathrm{mV}$ polarization and is meeting the NACE cathodic protection standard for cathodic protection (Figure 11) even though the anodes are in a dry environment beneath the silica fume concrete overlay and bridge deck waterproofing system installed on top.

\subsection{Florida DOT Marine Columns}

These Florida DOT marine bridges located in south Florida and the Florida Keys were suffering from corrosion due to chloride contamination from storm surges and atmospheric exposure (Figure 12).
MTO Galvanic CP Bridge Deck Overlay

\begin{tabular}{|l|l|l|l|l|}
\hline \multicolumn{1}{|c|}{ Date } & $\begin{array}{c}\text { Temp } \\
\text { C /F }\end{array}$ & $\begin{array}{c}\text { Current } \\
(\mathrm{mA})\end{array}$ & $\begin{array}{c}\text { Current/m2 } \\
(\mathrm{mA} / \mathrm{m} 2)\end{array}$ & Polarization (mV) \\
\hline Oct. 3, 2003 & $7 / 45$ & 169 & 6.5 & 273 \\
\hline May 10, 2004 & $20 / 68$ & 99 & 3.8 & 271 \\
\hline Jan 18, 2005 & $-20 /-4$ & 14 & .55 & 142 \\
\hline July 27, 2005 & $20 / 68$ & 47 & 1.8 & 313 \\
\hline Nov. 17, 2005 & $0 / 32$ & 30 & 1.1 & 276 \\
\hline Apr. 19, 2006 & $10 / 50$ & 38 & 1.4 & 285 \\
\hline July 26, 2006 & $25 / 76$ & 43 & 1.6 & 353 \\
\hline Apr. 11, 2007 & $-3 / 27$ & 27 & 1.0 & 201 \\
\hline Aug. 23, 2007 & $22 / 71$ & 41 & 1.5 & 501 \\
\hline Jan. 10, 2008 & $0 / 32$ & 29 & 1.1 & 322 \\
\hline May 12, 2009 & $21 / 70$ & 38 & 1.4 & 285 \\
\hline Sept. 25, 2010 & $19 / 66$ & 35 & 1.3 & 305 \\
\hline June 7, 2012 & $22 / 71$ & 46 & 1.8 & 278 \\
\hline Nov. 7, 2013 & $4 / 39$ & 29 & 1.13 & 388 \\
\hline July 7, 2015 & $25 / 76$ & 29 & 1.1 & 432 \\
\hline Oct. 6, 2015 & $13 / 55$ & 28 & 1.1 & 423 \\
\hline July Oct. 17, 2017 & $23 / 73$ & 16 & 0.6 & 202 \\
\hline & & & & \\
\hline
\end{tabular}

Fig. 11. MTO Galvanic CP bridge deck overlay performance data
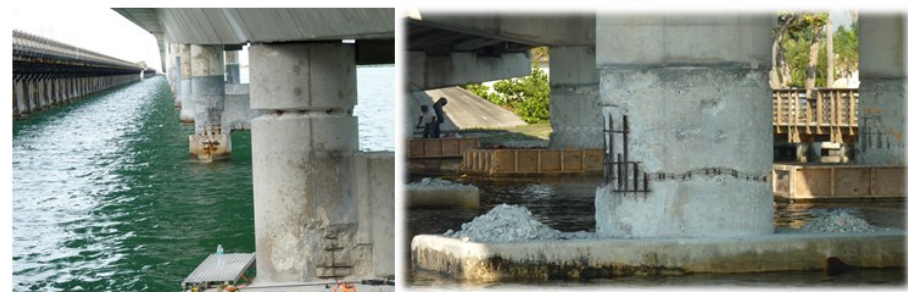

Fig. 12. Deteriorated columns and removal of damaged concrete

Florida DOT has utilized other corrosion protection options such as arc-sprayed zinc and zinc mesh jackets on this type of structure in the past with limited success. These projects utilized distributed alkali-activated galvanic anodes installed inside stay-in-place forms (Figure 13).
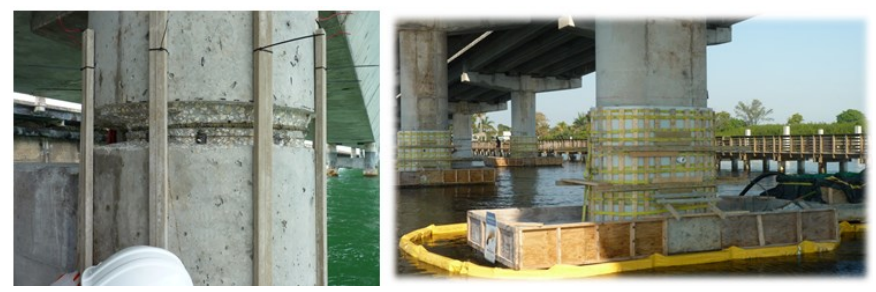

Fig. 13. Installation of alkali-activated galvanic anodes and jacket

The stay-in-place form can be fiberglass or PVC with PVC having the advantage of being modular and providing greatly improved durability and bonding with the concrete column. 


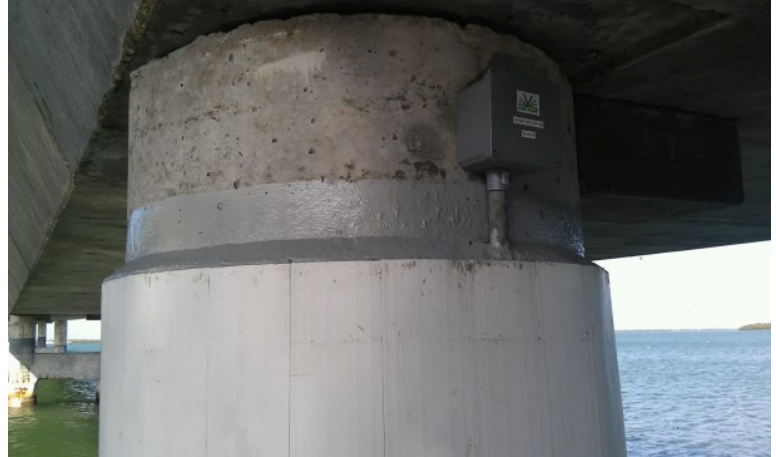

Fig. 14. Installed PVC galvanic cathodic protection jacket with monitoring station

As with all FDOT projects, monitoring provisions were provided when the column jackets were installed such that the long-term $\mathrm{CP}$ performance and effectiveness of each jacket could be verified (Figure 14).

FDOT has used zinc mesh galvanic jackets to protect reinforcing steel in the splash zone. Research has shown these jackets to be effective if they are kept wet, but the zinc mesh will become more passive and generate less protective current for each foot of elevation above the high tide line. Since these columns are fully above the high tide line activated zinc anodes were specified and installed (Figure 15).

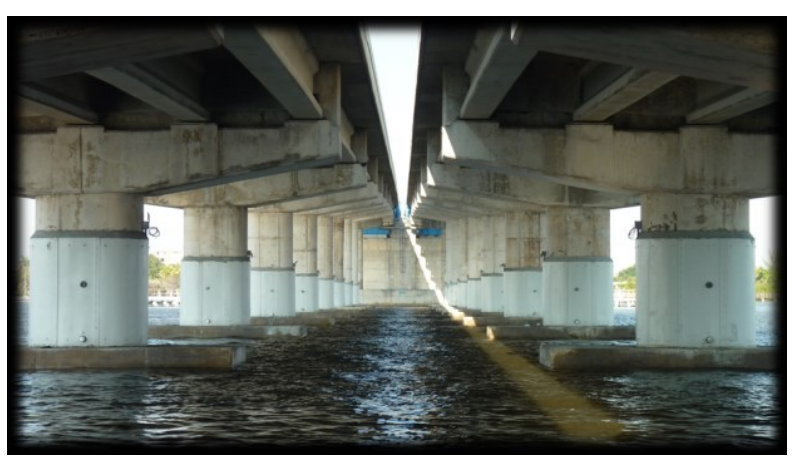

Fig. 15. Installed above-water alkali-activated galvanic cathodic protection jackets

The alkali-activated galvanic cathodic protection jackets are installed and are being monitored by FDOT. Monitoring parameters include potentials, current, polarization and service life. Due to the number of monitored columns, the raw data is too voluminous to present herein. Since the first columns were completed in 2012, the jacketed columns have met or exceeded the NACE cathodic protection criteria by polarizing the reinforcing steel more than $100 \mathrm{mV}$.

\section{Conclusions}

Alkali-activated discrete galvanic anodes installed in the 1990's remain active and have provided Cathodic Prevention (Corrosion Prevention) current densities to reinforcing steel adjacent to patch repairs for over 15 years. Examination of anodes verify there is sufficient zinc remaining to last 25 to 30 years. As such, alkali- activated discrete galvanic anodes in patch repairs provide low cost, simple corrosion protection to extend the service life of localized concrete repairs.

\begin{tabular}{|c|c|c|c|c|c|}
\hline & mA & On $(\mathbf{m V})$ & Off $(\mathbf{m V})$ & Pol. $(\mathbf{m V})$ & Notes \\
\hline Static/native & & -458 & & & \\
\hline On & 725 & & & & \\
\hline $\mathbf{1 6}$ hrs & 228 & -997 & -825 & -367 & vs static \\
\hline $\mathbf{9 0}$ days & 98 & -931 & -652 & -238 & 4 hours \\
\hline $\mathbf{1 1 8}$ days & 72 & -912 & -657 & -293 & 21 hours \\
\hline $\mathbf{2 7 0}$ days & $\mathrm{n} / \mathrm{a}$ & -905 & -667 & -205 & vs static \\
\hline $\mathbf{5 9 4}$ days & 67 & -867 & -664 & -236 & 2 hours \\
\hline
\end{tabular}

Fig. 16. Sample monitoring data from an alkali-activated galvanic cathodic protection jacket in the Florida Keys

As described in this paper, galvanic anode systems can also be designed to provide low maintenance cathodic protection to reinforced concrete structures. Systems can be designed to meet cathodic protection criteria in cold, temperate and warm environments. Alkali-activated galvanic cathodic protection systems do not introduce any corrosive constituents into the concrete structure and can be designed to provide low maintenance cathodic protection for 20 to $40+$ years.

Galvanic cathodic protection systems can be designed to provide long-term cathodic protection to structural concrete components in a range of environments including:

- Bridge substructures in temperate, de-icing salt environments,

○ Bridge decks in temperate, de-icing salt environments,

$\circ$ Bridge piles in marine tidal / splash zones, and

○ Bridge columns in tropical, marine environments above the tidal zone.

\section{References}

1. G. Sergi, C.L. Page, Sacrificial anodes for cathodic protection of reinforcing steel around patch repairs applied to chloride-contaminated concrete, Proc. Eurocorr '99, European Corrosion Congress, Aachen, Germany. (1999)

2. C.L. Page, G. Sergi, Developments in cathodic protection applied to reinforced concrete. J, Mat. in Civil Eng., Sp. Issue, Durability of Construction Materials: 8 $15(2000)$

3. G. Sergi, D. Simpson, J. Potter, Long-term performance and versatility of zinc sacrificial anodes for control of reinforcement corrosion. Proc. Eurocorr 2008, European Corrosion Congress, Edinburgh (2008)

4. G. Sergi, Ten-year results of galvanic sacrificial anodes in steel reinforced concrete. Materials and Corrosion 62 (2): 98-104. (2011)

5. L. Bertolini, F. Bolzoni, A. Cigada, T. Pastore, P. 
Pedeferri, Cathodic protection of new and old reinforced concrete structures, Corros. Sci. 35: 1633-1639. (1993)

6. P. Pedeferri, Cathodic protection and cathodic prevention, Construction and Building Materials 10(5): 391-402 (1996)

7. G. Sergi, Extension of residual service life by galvanic cathodic protection, In $\mathrm{K}$ van Breugel, G Ye \& Y Yuan (eds), Service Life Design for Infrastructure,. Proc., $2^{\text {nd }}$ Int. Symp., Vol. 2, RILEM Publications SARL: 613-621 (2010) 